Jurnal Indonesia Sosial Teknologi: p-ISSN: 2723 - 6609

e-ISSN : 2548-1398

Vol. 1, No. 4 November 2020

\title{
RANCANG BANGUN SISTEM INFORMASI WEBSITE EKSTRAKURIKULER SMK YAPPIKA LEGOK TANGERANG
}

\author{
Mochamad Nandi Susila, Badriyah, Andronias Siregar, Muhammad Darussalam \\ Universitas Bina Sarana Informatika \\ Email: mochamad.mnl@bsi.ac.id: bbadriyah86@gmail.com: andronias.aoe@bsi.ac.id: \\ muhammad.mds@bsi.ac.id
}

\begin{abstract}
Extracurricular is a program of activities outside of the regular teaching and learning activity agenda prepared by schools for students in order to develop the talents and interests of their students. Vocational High School Yappika Legok Tangerang is one of the top high school educational institutions that provides several extracurricular activities for its students. The current problem is that the extracurricular management of Yappika Legok Tangerang Vocational School is not maximal, starting from the registration process, monitoring, to activity reports that still rely on conventional systems. The purpose of this research is to design a website information system to support the management of extracurricular activities at SMK Yappika Legok Tangerang by utilizing database-based applications. The research method used uses data collection techniques andsoftware development methods waterfall in designing and building applications. So that this research produces a website information system with several levels of access rights according to the analysis carried out in the early stages of software development. The results of this information system, the parties involved as actors in extracurricular activities at SMK Yappika Legok Tangerang are very helpful in carrying out management and monitoring of extracurricular activities carried out
\end{abstract}

Keywords: Information Systems; Extracurricular Website; Waterfall Method)

\begin{abstract}
Abstrak
Ekstrakurikuler merupakan program kegiatan diluar dari agenda kegiatan belajar mengajar reguler yang disiapkan sekolah bagi peserta didiknya dalam rangka mengembangkan bakat dan minat dari peserta didiknya. SMK Yappika Legok Tangerang salah satu institusi pendidikan menegah atas yang memberikan beberapa kegiatan ekstrakurikuler kepada para siswanya. Permasalahan yang ada saat ini adalah kurang maksimalnya pengelolaan ekstrakurikuler SMK Yappika Legok Tangerang mulai dari proses pendaftaran, monitoring, hingga laporan kegiatan yang masih mengandalkan sistem konvensional. Tujuan dari penelitian ini adalah merancang bangun suatu sistem informasi website untuk menunjang pengelolaan kegiatan ekstrakurikuler pada SMK Yappika Legok Tangerang dengan memanfaatkan aplikasi yang berbasis pada basis data. Metode penelitian yang digunakan menggunakan teknik pengumpulan data dan metode pengembangan perangkat lunak waterfall dalam merancang bangun aplikasi. Sehingga penelitian ini menghasilkan suatu sistem informasi website dengan beberapa tingkatan hak akses
\end{abstract}


sesuai dengan analisa yang dilakukan pada tahapan awal pengembangan perangkat lunak. Hasil sistem informasi ini, pihak-pihak yang terlibat sebagai aktor dalam kegiatan ekstrakurikuler SMK Yappika Legok Tangerang sangat terbantu dalam menjalankan pengelolaan hingga monitoring kegiatan ekstrakurikuler yang dilakukan

Kata kunci: Sistem Informasi, Website Ekstrakurikuler, Metode Waterfall)

\section{Pendahuluan}

Perkembangan teknologi digital diseluruh sektor kehidupan memiliki dampak terhadap perubahan perilaku dalam pengelolaan suatu institusi, tidak terkecuali institusi pendidikan. SMK Yappika Legok Tangerang yang merupakan objek dari penelitian ini adalah salah satu institusi pendidikan menengah atas yang berlokasi di Kabupaten Tangerang melihat hal tersebut sebagai sebuah tantangan dalam memberikan pelayanan yang terbaik kepada para siswa peserta didiknya. Selain menjalankan Kegiatan Belajar Mengajar (KBM) sesuai dengan kurikulum yang diberlakukan oleh kementrian pendidikan dan kebudayaan, SMK Yappika Legok Tangerang juga memberikan program berupa kegiatan ekstrakurikuler kepada para siswanya, yang bertujuan untuk mengembangkan bakat dan minat masing-masing siswa yang berbeda-beda satu siswa dengan yang lainnya.

Permasalahan muncul, ketika kegiatan-kegiatan ekstrakurikuler yang ada pada objek penelitian ini memiliki tingkat pengelolaan dan monitoring yang masih terbilang lemah, seperti pendaftaran, monitoring kegiatan, hingga laporan kegiatan. Hal ini dikarenakan kurang maksimalnya pemanfaatan teknologi digital yang ada pada kegiatan operasional ekstrakurikuler SMK Yappika Legok Tangerang. Sebagai contoh, proses pendaftaran anggota dalam suatu ekstrakurikuler masih mengandalkan berkas fisik yang datanya tidak tersimpan secara komputerisasi. Dampak negatif yang muncul adalah pencarian data, hingga pmbuatan laporan kegiatan menjadi terhambat dan tidak maksimal dan akurat.

Kegiatan ekstrakurikuler sendiri adalah suatu kegiatan berada di luar program yang tertulis didalam kurikulum seperti latihan kepemimpinan dan pembinaan siswa. Kegiatan ekstrakurikuler ditujukan agar siswa dapat mengembangkan kepribadian, bakat, dan kemampuannya di berbagai bidang di luar bidang akademik (Dewi et al., 2016) . Dalam penelitian ini, kegiatan ekstrakurikuler dapat dikelola dengan baik dengan adanya suatu sistem informasi berbasis aplikasi, dalam hal ini usulan peneliti menggunakan basis website agar memudahkan user dalam mengakses aplikasi serta mendapatkan data-data yang dibuthkan secara tepat, karena data disimpan dalam suatu basis data yang sudah terintegrasi dengan sistem informasi yang dirancang bangun. Sistem sendiri dapat dikatakan sebagai seperangkat elemen yang digabungkan satu dengan lainnya untuk suatu tujuan bersama. Sistem dapat merupakan sesuatu yang abstrak dan maupun yang berwujud (Nafiudin SE MM, 2019).

Media pembelajaran yang sangat berpengaruh dan sangat dekat dengan para remaja atau peserta didik saat ini adalah internet. Keunggulan yang ditawarkan oleh 
teknologi komputer dan internet tidak hanya kecepatan untuk memperoleh informasi dari yang telah disediakan namun juga terdapat fasilitas multimedia yang dapat membuat belajar lebih menarik, visual, interaktif, dan menyenangkan sehingga akan menumbuhkan motivasi serta minat belajar peserta didik. Secara sederhana dapat dikatakan bahwa semua pembelajaran yang dilakukan dengan memanfaatkan teknologi internet dan selama proses belajar dirasakan terjadi oleh yang mengikutinya, maka kegiatan itu dapat disebut juga sebagai pembelajaran berbasis web, menurut Rusman dalam (Sari \& Suswanto, 2017). Sehingga operasional kegiatan ekstrakurikuler dalam penelitian ini perlu ditunjang dengan sistem informasi berbasis aplikasi web.

Aplikasi web adalah aplikasi yang disimpan dan dieksekusi di lingkungan web server. Setiap permintaan yang dilakukan oleh user melalui aplikasi klien (web server) akan di respon oleh aplikasi web dan hasilnya akan dikembalikan lagi ke hadapan user. Dengan aplikasi web, halaman yang tampil di layar web browser dapat bersifat dinamis, tergantung dari nilai data atau parameter yang dimasukkan oleh user (Raharjo, 2016). Aplikasi web sendiri aplikasi yang berjalan di browser web seperti Internet Exploler, Mozilla, Opera, dan lain-lain (Nugroho, 2017). Sistem Informasi dalam penelitian ini memiliki landasan website yang dapat juga, selain dijalankan pada komputer juga dapat berjalan pada platform smartphone karena bersifat dinamis atau responsive.

Salah satu bahasa pemrograman skrip yang dirancang untuk membangun aplikasi web yaitu PHP. Ketika dipanggil dari web browser, program yang ditulis dengan PHP akan di-parsing didalam web server oleh interpreter PHP dan diterjemahkan ke dalam dokumen HTML, yang selanjutnya akan ditampilkan kembali ke web browser, karena pemrosesan program PHP dilakukan di lingkungan web server, PHP dikatakan bahasa sisi server (server side) (Budi \& Imam Heryanto ERK, 2014). Sedangkan HTML (Hypertext Markup Languange) sebuah bahasa pemrograman markup yang berisi kodekode tag sehingga informasi tersebut dapat ditampilkan dihalaman web sehingga dapat dibuka menggunakan browser web seperti Mozila Firefox atau Microsoft Internet Exploler (Fauziah, 2014). Versi bahasa pemrograman yang dipakai dalam penelitian ini menggunakan versi php yang sudah uptodate saat ini dengan memadukan script-script html yang dibutuhkan.

Peneliti memanfaatkan pengelolaan data pada kegiatan ekstrakurikuler ini dengan basis data atau database yang terintegrasi dengan aplikasi. Database sendiri merupakan salah satu komponen penting dalam sistem informasi, karena merupakan dasar dalam menyediakan informasi (Riyanto, 2014). Khusus untuk pengelolaan data dengan basis data, peneliti menggunakan paket web server xampp yang memiliki kehandalan terkini dalam pengembangan sistem informasi website, dengan didalamnya sudah tersedia paket database management system untuk pengelolaan basis data.

Desain basis data yang peneliti gunakan menggunakan Entity Relationship Diagram (ERD). Suatu diagram yang menyatakan data dalam bentuk relasi antar entitas yang memiliki sekumpulan atribut. Relasi antar data dapat dijadikan landasan merancang tempat penyimpanan data baik secara logis maupun fisik. (Suprapto, 2018). 
Sementara sebagai penerapan pengkodean dalam penelitian ini, menggunakan framework yang popular dan terbaru dikalangan pengembang sistem informasi website yaitu, Codeigniter. Framework sendiri dapat diartikan sekumpulan perintah atau program dasar dimana perintah dasar tersebut dapat digunakan lagi untuk menyelesaikan masalah yang lebih kompleks sehingga dapat digunakan untuk membantu membuat aplikasi baru atau aplikasi kompleks tanpa harus membuat program dari awal (Priyanto Hidayatullah JKK, 2017).

Peneliti menggunakan model pengembangan perangkat lunak waterfall, model SDLC (Software Development Life Cycle) yang paling sederhana. Model ini hanya cocok untuk pengembangan perangkat lunak dan spesifikasi yang tidak berubah-ubah.(Sukamto \& Shalahuddin, 2016). Dengan menjalankan setiap tahapan yang ada pada metodologi waterfall, penelitian bertujuan untuk merancang dan mengimplementasikan sistem informasi yang baik khususnya pada pengelolaan kegiatan ekstrakurikuler SMK Yappika Legok Tangerang.

\section{Metode Penelitian}

Dalam penelitian ini menggunakan beberapa metode penilitian, seperti teknik pengumpulan data dan metode pengembangan perangkat lunak.

Teknik pengumpulan data dalam penelitian ini dilakukan beberapa tahapan, yaitu observasi dengan melakukan pengamatan langsung terhadap jalannya kegiatan dan pengelolaan ekstrakurikuler pada SMK Yappika Legok Tangerang,wawancara terhadap pihak-pihak yang berkaitan dengan tema penelitian, serta tidak terkecuali pengumpulan data dilakukan juga dengan studi kepustakaan yang peneliti ambil melalui buku-buku, literature jurnal yang didapat dari media internet.

Sementara untuk metode pengembangan perangkat lunak, peneliti menggunakan tahapan-tahapan pada metode waterfall, yaitu:

1. Analisa Kebutuhan Perangkat Lunak

Peneliti melakukan analisa terhadap permasalahan yang terjadi dalam pengelolaan kegiatan ekstrakurikuler SMK Yappika Legok Tangerang, dimulai dari prosedur pendaftaran anggota, monitoring, hingga ke pembuatan laporan kegiatan. Sehingga dihasilkan kebutuhan-kebutuhan user atau pemakai sistem informasi hasil penelitian.

2. Desain

Melanjutkan tahapan analisa, peneliti melakukan desain rancangan basis data beserta spesifikasi file-file yang dibutuhkan, serta melakukan desain terhadap rancangan tampilan user interface dari sistem informasi yang dibangun agar memiliki aspek kemudahan dalam penggunaan serta sesuai dengan kebutuhan user atau pemakai.

3. Pembuatan Kode Program

Tahapan ini salah satu faktor penting juga dalam penelitian ini, karena penulisan source kode program dari sistem informasi yang dibangun dituangkan dalam bahasa pemrograman dan framework yang digunakan.

4. Pengujian 
Setelah tahapan-tahapan awal terpenuhi dan diselesaikan, selanjutnya peneliti melakukan pengujian terhadap sistem informasi yang dibangun dengan menggunakan teknik pengujian blackbox testing, yaitu menjalankan seluruh fitur yang ada pada setiap form pada sistem informasi yang dibangun. Hal ini dilakukan untuk mengukur sejauh mana tingkat error dan ketidaksesuaian sistem informasi yang dibangun dengan kebutuhan-kebutuhan user atau pemakai.

\section{Hasil dan Pembahasan}

Berikut hasil dari penelitian ini yang peneliti deskripsikan dalam bentuk analisa kebutuhan sistem informasi yang dibangun:

1. Analisa kebutuhan pembina
a. Melihat data anggota (siswa)
b. Melihat data pelatih
c. Melihat data guru
d. Melihat laporan kegiatan ekstrakurikuler

2. Analisa kebutuhan pelatih ekstrakurikuler
a. Mengelola absensi kegiatan dan nilai anggota (siswa)
b. Mencetak laporan absensi kegiatan dan nilai anggota (siswa)

3. Analisa kebutuhan guru
a. Melihat laporan nilai siswa dalam hal ini anggota ekstrakurikuler
b. Mencetak laporan nilai siswa dalam hal ini anggota ekstrakurikuler

4. Analisa kebutuhan anggota (siswa)
a. Melakukan pendaftaran melalui sistem informasi
b. Melihat absensi kegiatan dan nilai anggota (siswa)

5. Analisa kebutuhan administror sistem
a. Mengelola seluruh data yang terlibat, seperti anggota (siswa), pelatih, pembina, guru, kegiatan ekstrakurikuler
b. Mencetak seluruh data yang ada pada sistem informasi

Berdasarkan hasil analisa diatas, selanjutnya peneliti akan membahas mengenai pembuatan desain rancangan basis data yang dibutuhkan, berikut ini desain Entity Relationship Diagram (ERD) sistem informasi yang dibangun: 
Mochamad Nandi Susila, Badriyah, Andronias Siregar, Muhammad Darussalam

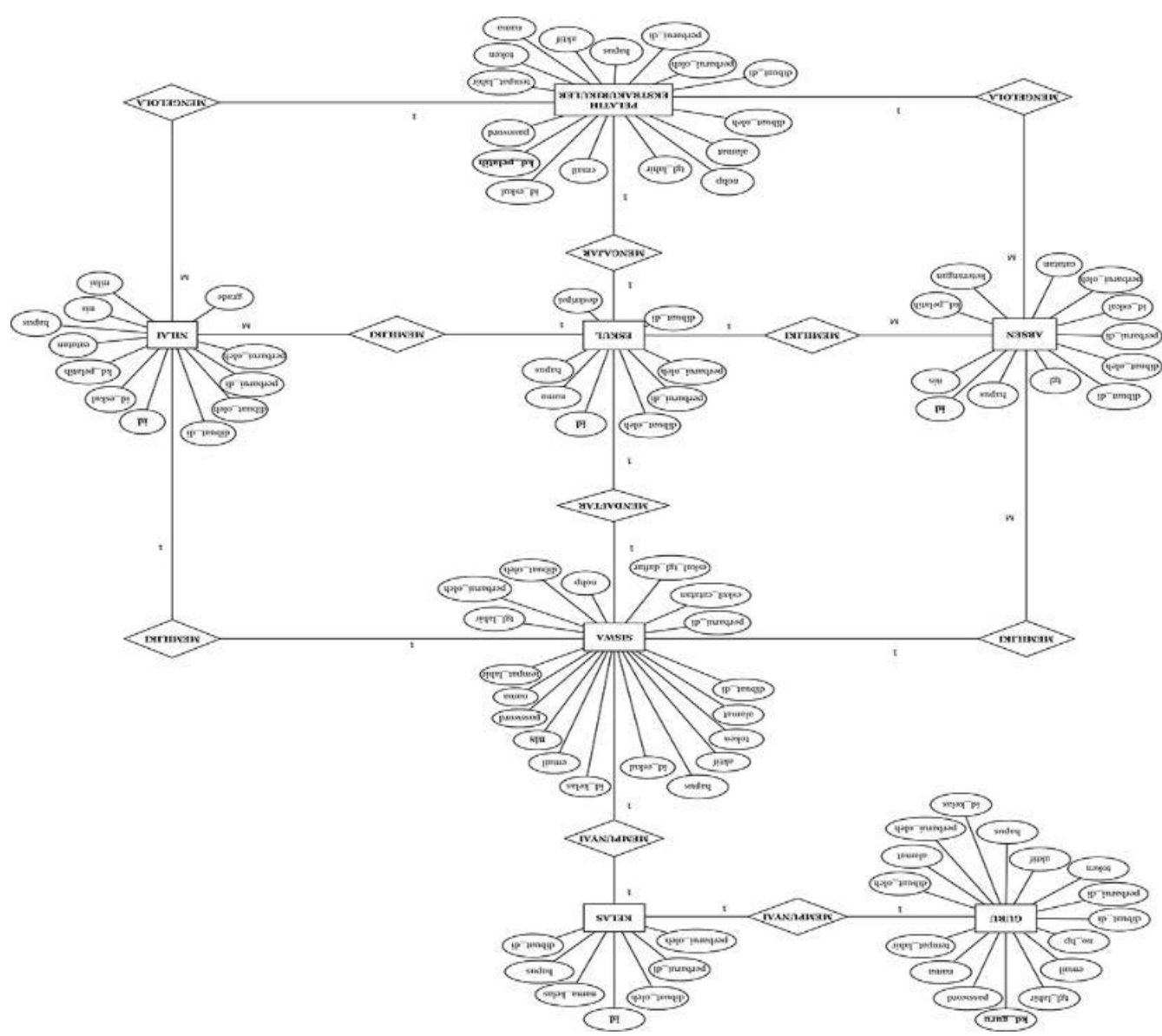

Gambar 1 ERD Sistem Informasi Website Ekstrakurikuler

Dengan melihat desain ERD diatas, maka penggambaran file-file yang akan dibuat pada basis data sebagai berikut: 
Rancang Bangun Sistem Informasi Website Ekstrakurikuler SMK Yappika Legok Tangerang

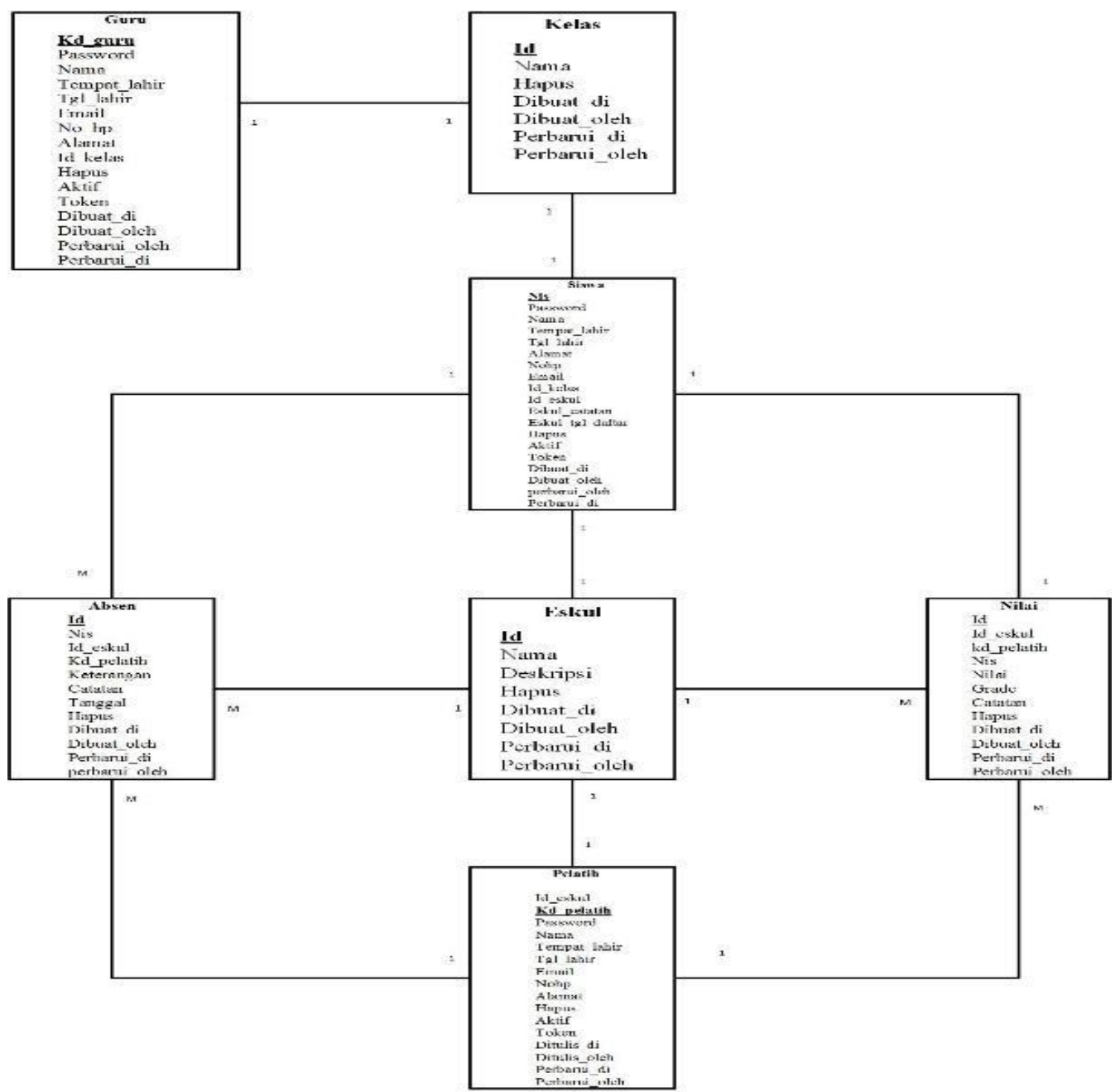

Gambar 2 Struktur File Basis Data

Selain basis data, peneliti juga melakukan rancangan tampilan umum sistem informasi yang dibangun, seperti pada gambar dibawah ini:

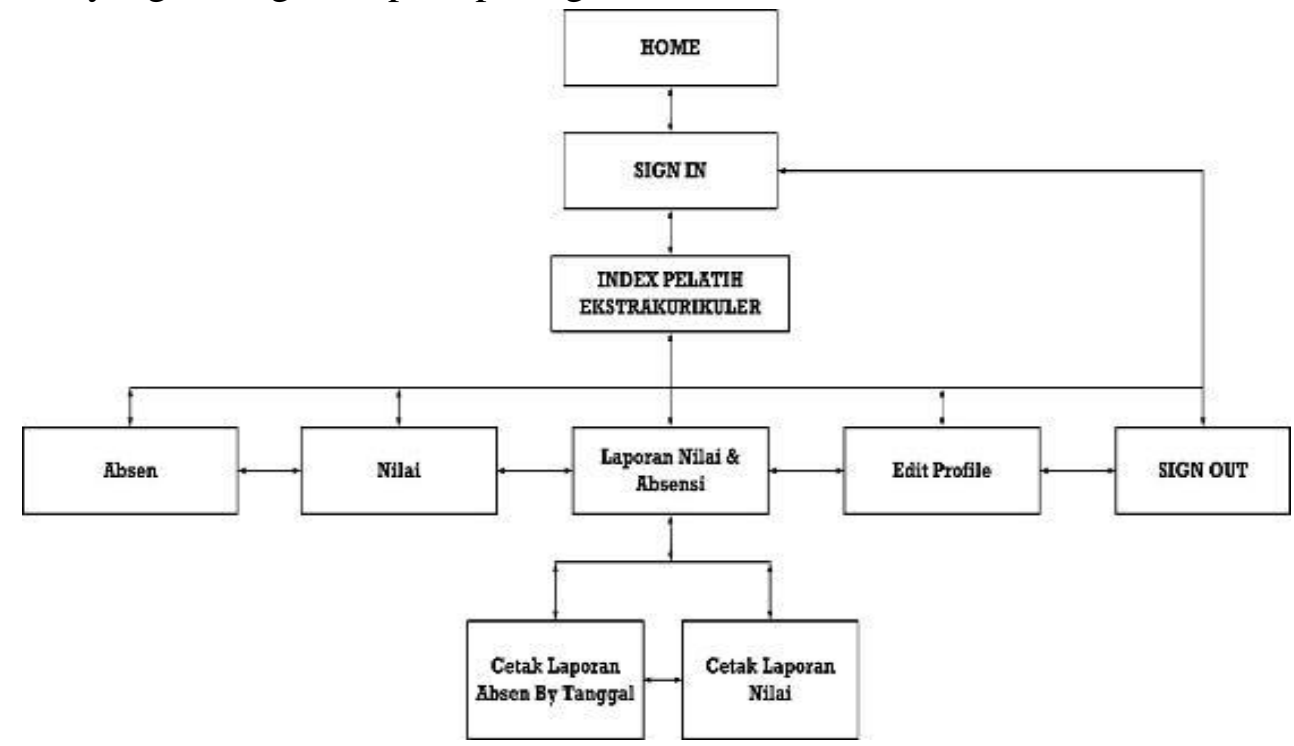

Gambar 3 Struktur Navigasi User Interface Pelatih Ekstrakurikuler 
Mochamad Nandi Susila, Badriyah, Andronias Siregar, Muhammad Darussalam

Dalam gambar diatas merupakan rancangan atau sketsa logis dari user interface utama untuk pelatih ekstrakurikuler, dimana kegiatan utama nya yaitu pengelolaan Absensi dan Nilai anggota (siswa) yang menjadi tanggungjawabnya.

Kemudian tahapan penulisan source kode program penelitian ini menggunakan framework CodeIgniter yang ditulis dengan Bahasa pemrograman PHP dan HTML dan tersimpan didalam web server, berikut pembahasan hasil penggambarannya:

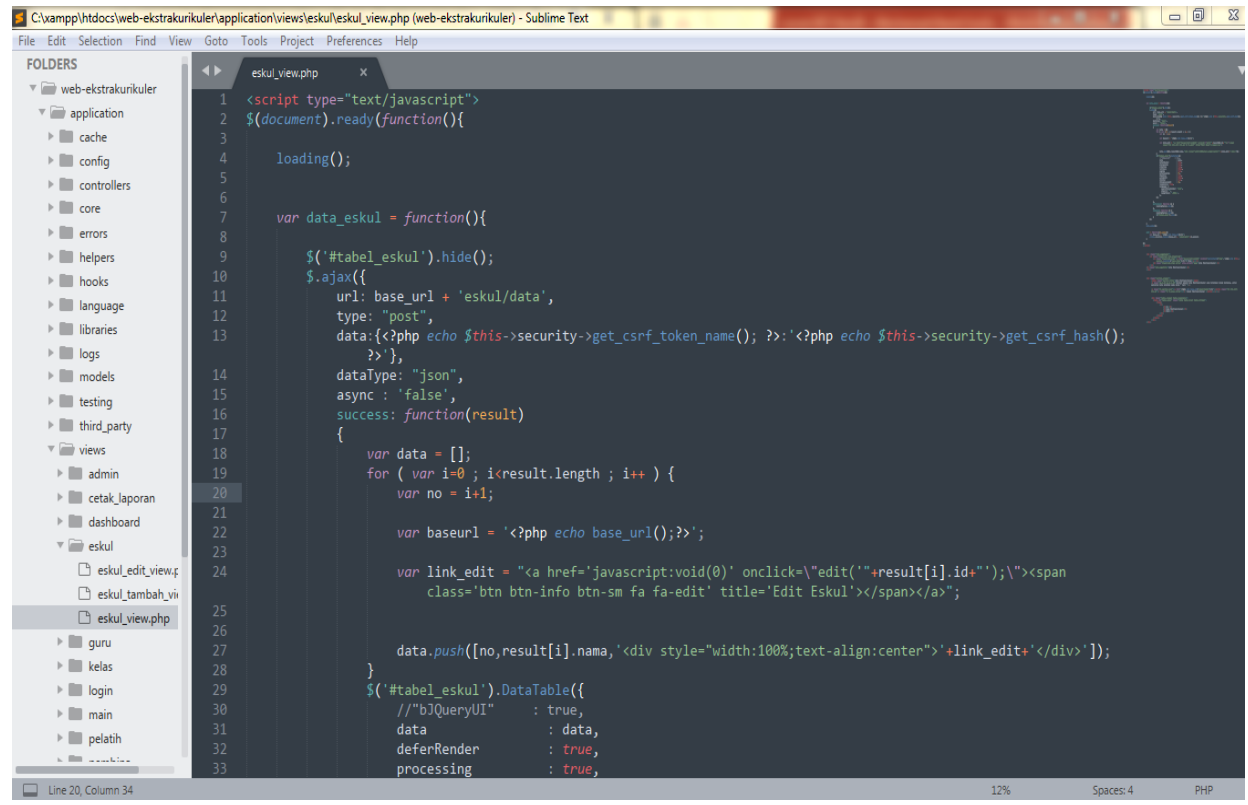

Gambar 4 Tahapan Pengkodean Source Code

Dibawah ini merupakan beberapa hasil tampilan implementasi dari sistem informasi websiter ekstrakurikuler yang dibangun pada SMK Yappika Legok Tangerang:

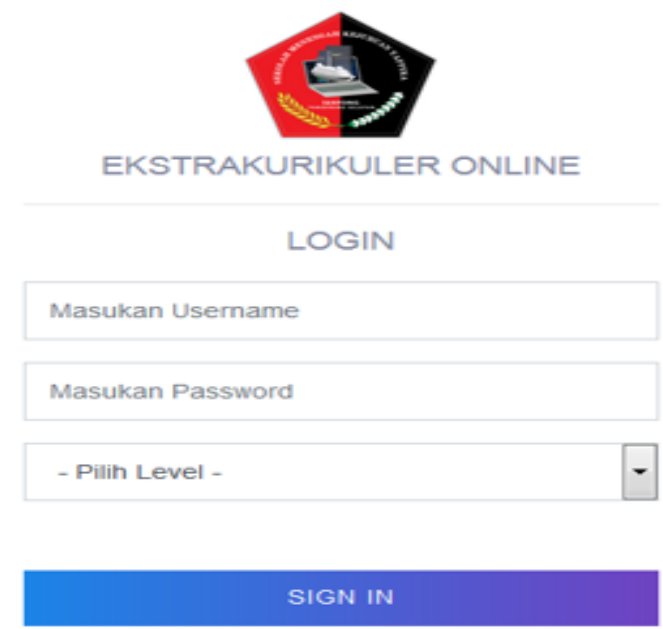

Gambar 5 Tampilan Implementasi Login Form 


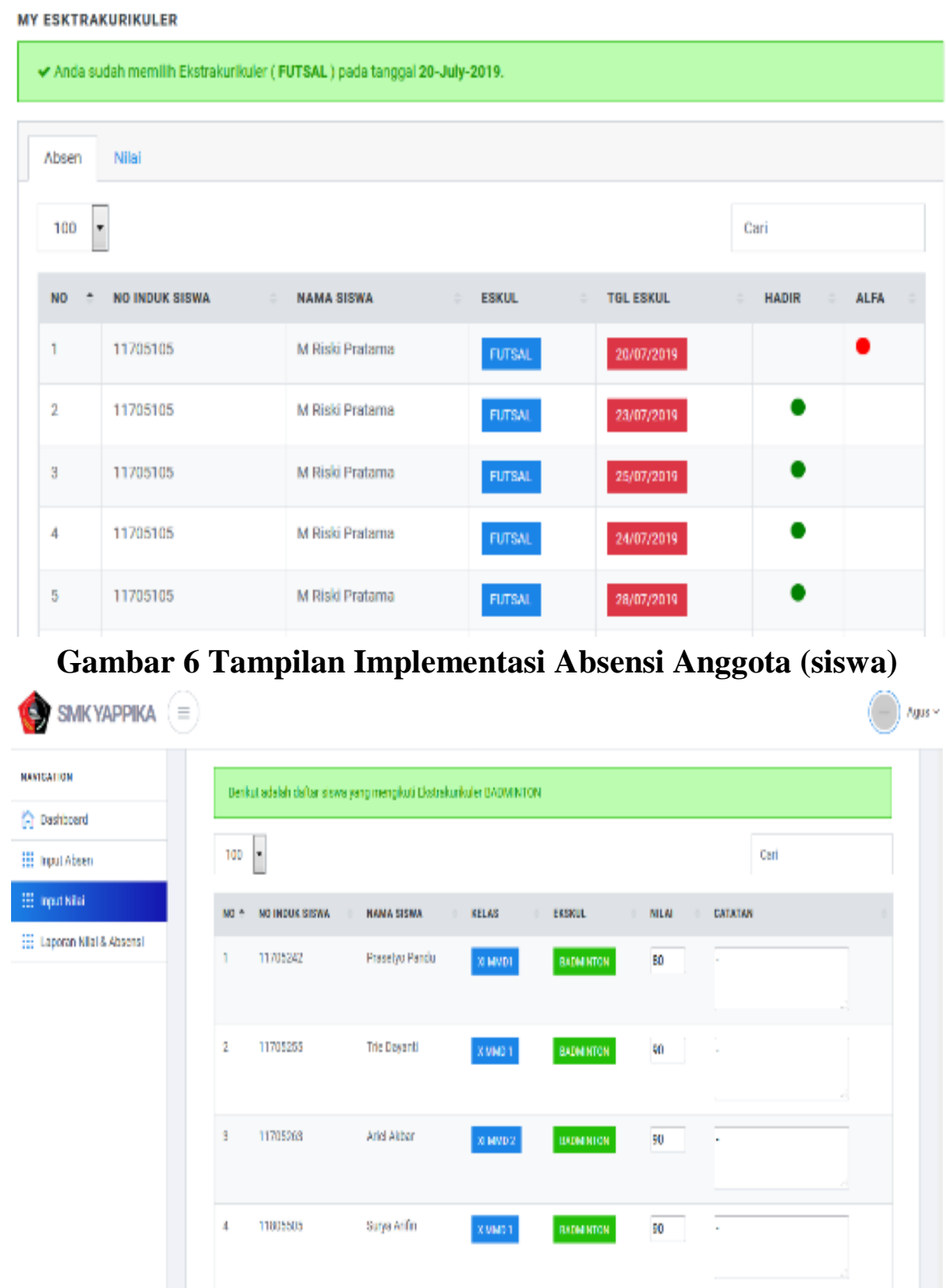

Gambar 7 Tampilan Implementasi Nilai Anggota (siswa)

\section{Kesimpulan}

Berdasarkan hasil dari penelitian yang dilakukan, maka penulis dapat mengambil kesimpulan, bahwa penggunaan dan pemanfaatan teknologi digital mampu membawa dampak positif bagi kemudahan pengelolaan kegiatan ekstrakurikuler, seperti dalam hal kecepatan dalam proses pendaftaran anggota (siswa), monitoring absensi kegiatan, pemberian nilai oleh pelatih, semua dilakukan secara digital dengan berlandaskan basis website. Kehilangan data atau kerusakan berkas yang semula berbasis berkas fisik pun mulai digantikan dengan basis data yang terintegrasi dengan aplikasi, sehingga dalam hal pencarian dan pencetakan data menjadi lebih efektif dan efisien. 
Mochamad Nandi Susila, Badriyah, Andronias Siregar, Muhammad Darussalam

\section{Bibliografi}

Budi, R., \& Imam Heryanto ERK. (2014). MODUL PEMROGRAMAN WEB HTML HTML, PHP \& MYSQL (Revisi Ked). Bandung: Modula.

Dewi, S., Wijayanti, A., Wikusna, W., BR, A., FI, T., \& U, T. (2016). APLIKASI EKSTRAKURIKULER.

https://openlibrary.telkomuniversity.ac.id/pustaka/121905/aplikasi-

Ekstrakurikuler-Berbasis-Web-Dan-Sms-Gateway-Studi-Kasus-Smpn-34-

Bandung-.html, 996-1002.

Fauziah. (2014). Konsep Dasar Perancangan WEB. Mitra Wacana Media.

Nafiudin SE MM. (2019). Sistem Informasi Manajemen. Qiara Media. Retrieved from https://books.google.co.id/books?id=m6esDwAAQBAJ\&printsec=frontcover\& $\mathrm{dq}=$ sistem $\& \mathrm{hl}=\mathrm{id} \& \mathrm{sa}=\mathrm{X} \& \mathrm{ved}=0 \mathrm{ahUKEwiY7Jn2ypLnAhW27XMBHTI5CSUQ}$ 6AEIMDAB\# $\mathrm{v}=$ onepage $\& \mathrm{q}=$ sistem $\& \mathrm{f}=$ false

Nugroho, A. (2017). Pemrograman Berorientasi Objek Menggunakan C\#. Bandung: Modula.

Priyanto Hidayatullah JKK. (2017). PEMROGRAMAN WEB EDISI REVISI. Bandung: Informatika.

Raharjo, B. (2016). MODUL PEMROGRAMAN WEB (HTML, PHP \& MySQL/MariaDB) EDISI KEEMPAT (ke empat) (4th ed.). Bandung: Modula.

Riyanto. (2014). Membuat Aplikasi Mini Market Integrasi Bercode Reader dengan PHP dan MySQL. Yogyakarta: Gava Media.

Sari, H., \& Suswanto, H. (2017). Pengembangan Media Pembelajaran Berbasis Web Untuk Mengukur Hasil Belajar Siswa Pada Mata Pelajaran Komputer Jaringan Dasar Program Keahlian Teknik Komputer Dan Jaringan. Jurnal Pendidikan. Retrieved from http://journal.um.ac.id/index.php/jptpp/

Sukamto, R., \& Shalahuddin, M. (2016). Rekayasa Perangkat Lunak (Terstruktur dan Berbasis Objek). Bandung: Informatika.

Suprapto, F. (2018). REKAYASA PERANGKAT LUNAK. Jakarta Pusat: Lentera ilmu cendekia. 